\title{
Impacts of Metacognition Management System (MMS) Training Course on Metacognitive Competencies
}

\author{
Fariba Dezhbankhan ${ }^{1}$, Diana Lea Baranovich ${ }^{1}$, Nabeel Abedalaziz ${ }^{1} \&$ Soraya Dezhbankhan $^{2}$ \\ ${ }^{1}$ Department of Educational Psychology and Counselling, Faculty of Education, University of Malaya, Malaysia \\ ${ }^{2}$ Calgary Board of Education, Canada \\ Correspondence: Fariba Dezhbankhan, Department of Educational Psychology and Counselling, Faculty of \\ Education, University of Malaya, Malaysia. E-mail: fdezhban@gmail.com
}

\author{
Received: May 29, $2020 \quad$ Accepted: September 1, $2020 \quad$ Online Published: December 26, 2020 \\ doi:10.5539/ies.v14n1p12 URL: https://doi.org/10.5539/ies.v14n1p12
}

\begin{abstract}
Metacognition is one of the vital competencies to seize the opportunities and overcome the challenges of twenty-first century; however, there is no precise definition of metacognition and it is a fuzzy concept. While classic, descriptive and procedural models try to describe the nature and ingredients of metacognition, theoretical clarity in terms of better definition and representation of its components is needed. This study by adopting theoretical models of metacognition through the Plan-Do-Check-Act principles (as a management instrument) proposes a conceptual framework, "Metacognition Management System (MMS)" that consolidates components, functions, and processes of metacognition in a single window. Then, impacts of a multidimensional intervention designed based on the MMS concept (MMS Training Course) provided in 12 hours, on 31 students' metacognitive competencies was investigated using quasi-experimental pre-test, post-test design. The large effect size (Partial $\eta^{2}$ $=.939,95 \%$ confidence interval) implied that MMS training course has a statistically significant impact on metacognitive competencies. This study has implications for further theoretical and experimental researches on the configuration and application of the MMS as well as designing multidimensional metacognitive intervention.
\end{abstract}

Keywords: metacognition, Metacognition Management System (MMS), Plan-Do-Check-Act (PDCA)

\section{Introduction}

Since Flavell's first attempt to construe metacognition as 'thinking about thinking' (Flavell, 1979, p. 906), various accounts of the term have been emerged, and the conceptualization of metacognition has been expanded to cover psychological phenomena instead of just cognitive phenomena (Papaleontiou-Louca, 2014). She also claims that there is no precise and commonly accepted definition of metacognition since it involves various epistemological processes (Peña-Ayala \& Cárdenas, 2015). In fact, the broad meaning and nature of metacognition makes it a fuzzy concept (Efklides, 2006). Veenman (2012) attributes fuzziness of metacognition to its constituents, the proliferation of terminologies, lack of consensus about the metacognition ingredients and their interrelationships.

During the evolution of metacognition, distinction was made between metacognitive knowledge, metacognitive regulation and metacognitive experience and different theoretical models were developed to conceptualize nature, ingredients, functionalities, facets and processes of metacognition. However, Azevedo and Aleven (2013) believe that theoretical clarity in terms of better definition of metacognition and representation of its ingredients is needed to be able to integrate studies regarding metacognition in a clear way (Zohar \& Dori, 2011).

In order to contribute in preparation of a single-entry point for relevant metacognition data, we propose a conceptual framework, 'Metacognition Management System' (MMS), in which all known phenomena entailed in different theoretical models of metacognition are integrated using management science principles. However, there is a limitation of theoretical integration of different models of metacognition and incorporation of management science to develop of a conceptual framework, which includes functions, components, facets, and processes of metacognition while showing developmental nature of the construct in a single window.

In the present study, we, try to answer to the following questions: (i) how phenomena involved in classic, descriptive and procedural models of metacognition can be integrated? and (ii) which approach (interdisciplinary or application of other disciplines) should be employed to establish interrelationship among phenomena involved in these models? Finally, after establishing our conceptual framework of metacognition (MMS) we investigate the 
impacts of training such management system on metacognitive competencies of students?

\section{Metacognition Management System (MMS)}

\subsection{Models of Metacognition}

Three groups of theoretical models are employed to describe the nature and components of metacognition and their interactions. Classic models describe the nature of metacognition, descriptive models underline components, functionalities, and facets of metacognition and their relationships and procedural models highlight a series of sequential stages or processes of metacognition (Peña-Ayala \& Cárdenas, 2015). Table 1 shows these models and phenomena involved in each.

Table 1. Theoretical models of metacognition

\begin{tabular}{|c|c|c|}
\hline & Models & Phenomena involved \\
\hline \multirow{11}{*}{$\begin{array}{l}\frac{n}{0} \\
\frac{0}{0} \\
\sum \\
0 \\
0 \\
\frac{0}{0} \\
\frac{0}{0}\end{array}$} & & Knowledge: know-how about cognitive enterprises \\
\hline & Flavell's Metacognitive Monitoring & Experience: familiar cognitive performance \\
\hline & Model (1979) & Goals-Tasks: outcomes to be realized by a task \\
\hline & & Strategies: processes needed for controlling accomplishment of cognitive goals \\
\hline & Norman and Shallice's & Executive system: perceptual and cognitive functions of the instance level \\
\hline & Executive-Object Model (1986) & Instance level: schemas as basic units of action and thought \\
\hline & Brown's Knowledge and Regulation of & Knowledge of cognition: information about cognitive processes \\
\hline & Cognition Model (1987) & Regulation of cognition: activities initiated by self-regulatory mechanisms \\
\hline & $\begin{array}{l}\text { Nelson and Narens's Hierarchical } \\
\text { Model (1994) }\end{array}$ & $\begin{array}{l}\text { Metal-level and Object-level cognitive processes } \\
\text { Control versus monitoring in terms of the flow of information from Metal-level and } \\
\text { Object-level, respectively }\end{array}$ \\
\hline & Shimamura (2008) & Meta-level (conceptualized as monitoring and controlling the object level) \\
\hline & smimamura (2008) & Object-level (to carry out task performance) \\
\hline \multirow{13}{*}{ 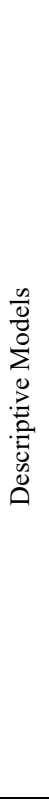 } & & Declarative metacognitive knowledge: knowledge about contents of mind \\
\hline & Alexander and Schwanenflugel's & Cognitive monitoring: ability to monitor mental state \\
\hline & Model (1996) & $\begin{array}{l}\text { Regulation of strategies: ability to achieve goals by using metacognitive knowledge } \\
\text { strategically) }\end{array}$ \\
\hline & & metacognitive knowing (declarative knowledge) \\
\hline & Kuhn’s Model (2000) & meta-strategic knowing (procedural knowledge) \\
\hline & & epistemological knowing (general knowledge) \\
\hline & Tobias and Everson's Componential & Monitoring prior learning \\
\hline & Model (2002) & ability to plan, monitor, evaluate and select strategies \\
\hline & Efklides's Model (2006) & $\begin{array}{l}\text { Monitoring: is reflected by metacognitive knowledge (ideas, beliefs, theories of goals, task, } \\
\text { person, and cognitive function facets) and Metacognitive experiences (feelings of } \\
\text { familiarity, difficulty, and judgments of learning facets) }\end{array}$ \\
\hline & & $\begin{array}{l}\text { Control: is articulated by metacognitive skills (the conscious for effort and time allocation } \\
\text { facets }\end{array}$ \\
\hline & Schraw et al. Model (2012) & $\begin{array}{l}\text { Metacognitive knowledge (declarative, procedural, and conditional) } \\
\text { metacognitive skills (information management, debugging, planning, monitoring and } \\
\text { evaluation) }\end{array}$ \\
\hline & Zohar's Meta-Strategic Knowledge & higher-order thinking strategies \\
\hline & Model (2012) & knowledge about persons, tasks, and strategies \\
\hline \multirow{4}{*}{ 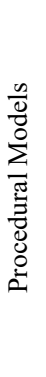 } & $\begin{array}{l}\text { Flavell's awareness of uncertainty } \\
\text { model (2003) }\end{array}$ & uncertainty in children through four stages \\
\hline & $\begin{array}{l}\text { Zelazo Conscious Awareness Model } \\
(2004)\end{array}$ & information processing and consciousness in structured hierarchical stages \\
\hline & Veenman's Model (2011) & $\begin{array}{l}\text { bottom- up metacognitive processes } \\
\text { top-down metacognitive processes }\end{array}$ \\
\hline & $\begin{array}{l}\text { Efklides's metacognitive and affective } \\
\text { model of self-regulated learning (2011) }\end{array}$ & $\begin{array}{l}\text { Person level: Intrapersonal traits interactions and their role in top-down self-regulation } \\
\text { Task } x \text { Person level: metacognitive experiences and affective states and their role in task } \\
\text { motivation and bottom-up self-regulation }\end{array}$ \\
\hline
\end{tabular}

Source: Adapted from: Peña-Ayala and Cárdenas (2015) 


\subsection{Metacognitive Skills, Strategies or Processes}

There are fuzzy boundaries between metacognitive skills and strategies both in definition and components. Gama (2004) suggests the term metacognitive strategy for the conscious and deliberate use of a specific method and metacognitive skill to define a refined strategy that is used automatically and unconsciously as needed. Based on the above definition she suggests 'selection of metacognitive strategies' as a metacognitive skill, among others (Gama, 2004, p. 12). On the Contrary, Panahandeh and Esfandiari (2014) define strategy as a high level executive skill using its components (planning, monitoring, and evaluating); hence, they categorize planning and monitoring as metacognitive strategies. On the other hand, some of these skills or strategies are known as processes by other researchers such as monitoring (Krizan \& Hisler, 2016; Koole \& Aldao, 2016; Papies \& Aarts, 2016; Hoyle \& Daviss, 2016) and evaluation (Papies \& Aarts, 2016; Hoyle \& Daviss, 2016). A sample of proposals for elucidating the most referred metacognitive skills or strategies are summarized in Table 2.

Table 2. Metacognitive skills/metacognitive strategies

\begin{tabular}{|c|c|c|}
\hline & Are known as metacognitive skill by: & Are known as metacognitive strategy by: \\
\hline $\begin{array}{l}\text { Goal } \\
\text { orientation/goal } \\
\text { setting }\end{array}$ & $\begin{array}{l}\text { Veenman, 2011; Desoete, 2007a, 2007b; Veenman, Van } \\
\text { Hout-Wolters, \& Afflerbach, 2006; Desoete \& Roeyers, 2005; } \\
\text { Sperling et al., 2004; Pintrich et al., 2000; Zimmerman, 2000; }\end{array}$ & \\
\hline Planning & $\begin{array}{l}\text { Veenman, 2011; Lazonder and Rouet, 2008; Desoete, 2007a, 2007b; } \\
\text { Veenman, Van Hout-Wolters, \& Afflerbach, 2006; White \& } \\
\text { Frederiksen, 2005; Desoete \& Roeyers, 2005; Sperling et al., 2004; } \\
\text { Hollingworth \& McLoughlin, 2001; Pintrich et al., 2000; } \\
\text { Zimmerman, 2000; }\end{array}$ & $\begin{array}{l}\text { Schraw \& Gutierrez, 2015; Eker, 2014; } \\
\text { Blummer \& Kenton, 2014; Csíkos \& Steklács, } \\
\text { 2010; Azevedo and Cromley, 2004; Gourgey, } \\
\text { 2001; Panahandeh \& Esfandiari, 2014. }\end{array}$ \\
\hline Organizing & & $\begin{array}{l}\text { Schraw \& Gutierrez, 2015; Bryce, 2007; Bryce } \\
\& \text { Whitebread, 2008) }\end{array}$ \\
\hline Monitoring & $\begin{array}{l}\text { Veenman, 2011; Lazonder and Rouet, 2008; Desoete, 2007a, 2007b; } \\
\text { Veenman, Van Hout-Wolters, \& Afflerbach, 2006; Desoete \& } \\
\text { Roeyers, 2005; White \& Frederiksen, 2005; Sperling et al., 2004; } \\
\text { Pintrich et al., 2000; Zimmerman, 2000; }\end{array}$ & $\begin{array}{l}\text { Schraw \& Gutierrez, 2015; Eker, 2014; } \\
\text { Blummer \& Kenton, 2014; Csíkos \& Steklács, } \\
\text { 2010; Azevedo and Cromley, 2004; Gourgey, } \\
\text { 2001; Panahandeh \& Esfandiari, 2014. }\end{array}$ \\
\hline Evaluation & $\begin{array}{l}\text { Veenman, 2011; Lazonder and Rouet, 2008; Desoete, 2007a, 2007b; } \\
\text { Veenman, Van Hout-Wolters, \& Afflerbach, 2006; Desoete \& } \\
\text { Roeyers, 2005; Sperling et. Al., 2004; Zimmerman, 2000; }\end{array}$ & $\begin{array}{l}\text { Schraw \& Gutierrez, 2015; Csíkos \& Steklács, } \\
\text { 2010; Gourgey, 2001; Panahandeh \& } \\
\text { Esfandiari, 2014. }\end{array}$ \\
\hline
\end{tabular}

Taking the approach of Krizan and Hisler (2016), Koole and Aldao (2016) and Papies and Aarts (2016) we argue that the so-called metacognitive skills or strategies are metacognitive processes.

\subsection{MMS Conceptual Framework}

Integrating classic and descriptive models of metacognition and considering the fact that metacognition develops during the time individuals mature (Peña-Ayala \& Cárdenas, 2015; Kuhn, 2000) based on procedural models, we propose a conceptual framework in which phenomena involved in these models are incorporated. Such framework comprises components (e.g. knowledge, regulation and experience), processes (e.g. planning and monitoring), and functions (e.g. motivation) of metacognition and evolves from continuous improvement cycle called Plan-Do-Check-Act (PDCA), which is a management method (Kymal, Gruska, \& Reid, 2015) to demonstrate the developmental nature of metacognition. This integration makes up 'Metacognition Management System (MMS)'.

A management system is a set of interrelated and interacting elements for establishing goals and objectives and empowering these goals and objectives to be attained efficiently and effectively. Using PDCA cycle, the management system integrates all elements such as functions, resources and processes into one logical and coherent system. Today, many organizations adopt a variety of management systems (and its traditional principles (PDCA)) to formalize and validate their managerial endeavours and tasks (Boiral \& Heras-Saizarbitoria, 2015). 'The origin of PDCA cycle is found in Dr. W. Edwards Deming's lecture in Japan in 1950. It is the most utilized methodology in business to control and continual enhancement of processes and products.

It should be noted that PDCA can be applied in macro (i.e. organizational) and micro (individual) levels (Liedtke, 2012). For example, Hasan and Hossain (2018) studied the applying PDCA in learning software-based skills among students. In their studies, time management, reducing unproductive activities such as searching in social 
media, and enhancing motivation to learn was the activities in the 'Plan' phase. Learning, based on the planned time and think about emerging issues during the leisure period (i.e. before sleeping) was the activities among others in 'Do' phase. Testing the accuracy of their learning was the activity of the 'Check' phase. Trying to solving problems and recording the weaknesses were the activities in the last phase, 'Act'. Results reflected that students who applied PDCA process could develop their software-based skills.

Zhao (2014) also investigated the effects of using PDCA on the improvement of writing skills of 194 non-English major second-year university students using a pre-test-post-test research design. Treatment included training of a certain kind of strategy and writing under the PDCA cycle. The findings revealed significant impacts of the treatment on using metacognitive, cognitive and social-affective strategies that lead to improvement in writing quality and writing proficiency.

The conceptual repetitive four-stage model of the MMS processes is illustrated in Figure 1.

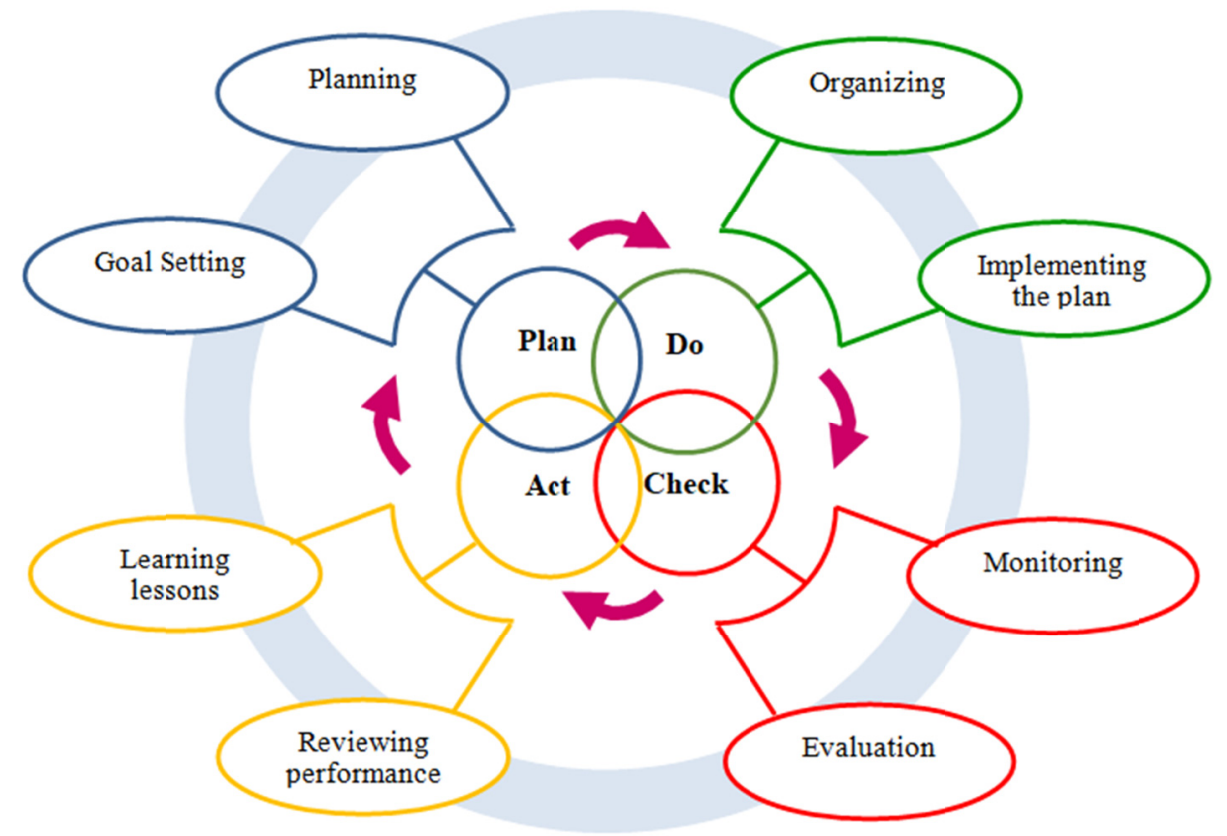

Figure 1. Metacognition Management System (MMS) processes (Source: Adapted from Abuhav, 2017)

MMS depicts the elements of such a model and takes into consideration key aspects of management sciences including:

Plan. The first step of the PDCA cycle is 'Plan', which involves setting goals and determining course of actions for achieving those goals (planning). Defining a policy, setting goals and creating a plan to meet these goals are common activities in planning phase of all management systems. Goal setting include adopting, adapting, or rejecting a goal (Locke \& Latham, 2013). While goal setting enables individuals to think of the task objectives, and its characteristics as well as available time (Desoete, 2011), formulating a plan helps individuals to take steps toward the goal smoothly without extensive pauses between sub-goals (Wickens \& Carswell, 2012).

There is a consensus that conscious planning is helpful for goal accomplishment even when it needs a course of action that entails distraction from individual's consistent behavior (Papies et. al., 2009; Holland et. al., 2006; Gollwitzer \& Sheeran, 2006). Planning as stated by Locke \& Latham (2013) refers to processes that involve in preparing to pursue a goal. According to Veenman (2011), serialization and sequencing are two processes of planning. Azevedo and Cromley (2004) believe that planning in educational setting applies to the development of a procedure for learning that requires activation of applicable prior knowledge.

Do. The second step involves organizing and implementing the plan. Organizing entails (i) developing a framework within which effort is coordinated; (ii) selecting appropriate strategies for managing information (Schraw \& Gutierrez, 2015); and (iii) allocating resources to different parts of subdivided activities identified in the developed framework. Resources may include, among others, (i) individual or internal resources such as 
cognitive capacities (attention, memory (Schunk, 2014), motivational beliefs (Whitebread \& Cárdenas, 2012; Pintrich \& Schunk, 2002), intelligence (Rozencwajg, 2003), experience, prior knowledge and epistemological beliefs (Whitebread \& Cárdenas, 2012) and (ii) environmental or external resources such as time and supportive social environment for metacognition (Lin, 2001). The executing phase (implementing the plan) includes chronological execution of the activities that have previously planned and determined (Kartikowati, 2013). The quality of the output is a function of (i) the manner in which activities are performed during this phase; and (ii) the individuals' commitment to attain their goals (Locke \& Latham, 1990).

Check. This step, which involves monitoring and evaluation, provide feedback about the operations as well as functioning of the plan (Kettner et al., 2008). The aim of this step is providing data that is useful for improving performance and attaining planned outcomes. Monitoring like other elements of the MMS describes in numerous ways. For example, monitoring is defined as an ongoing process by which individuals acquire regular information and feedback regarding the progress being made (i) towards attaining their goals and objectives (Morgeson et. al., 2012; Wilson \& Conyers, 2016); and (ii) in implementing actions or activities (Wilson \& Conyers, 2016). Whitebread and Cárdenas (2012) expand the term to cover awareness of feelings of knowing and awareness of affects and motivation. According to Hacker et. al., (2009), monitoring refers to awareness of one's both current thoughts and behavior (actions). Monitoring as stated by Wickens and Carswell (2012) involves keeping track of the quality of performance once a task is under way. Desoete (2011) believe that monitoring enables individuals to assess the sufficiency of particular strategy use, which may lead to apply a different strategy.

Evaluation is a systematic, meticulous and objective appraisal of an ongoing or completed plan, its implementation and outcomes. The purpose is to realize the relevance and achievement of objectives, quality, and effectiveness of the Plan (McDavid \& Hawthorn, 2006). Therefore, evaluation focuses on both critical results or outcomes and processes that lead to specific outcomes (Boehm-Davis \& Holt, 2004; Wickens \& Carswell, 2012). As stated by Veenman (2011) and Schraw \& Gutierrez (2015) evaluation is retroactive reflections that occur after happening and has transpired by which individuals scrutinize the strategies were used and their effectiveness. In fact, evaluation of the plan tends to answer to the following questions: (i) did the plan achieve its intended results? (ii) was the plan implemented as expected? and (iii) what was the plan's impact?

Based on the above one can conclude that: (i) monitoring lays the groundwork for evaluation by helping individuals to ensure that the plan is implemented as intended (Kettner et al., 2008); (ii) monitoring gives actual time information while evaluation is more in-depth assessment; (iii) monitoring can give rise to questions to be responded by evaluation;

Act. This step involves the actions needed to address any issues found in the previous step, 'Check'. Information collected during monitoring and evaluation phase analyzes and reviews to: (i) determine the differences between actual and planned results and their root causes; and (ii) to pinpoint where modification may be needed (Wilson \& Conyers, 2016). The knowledge gained and lessons learned from reviewing, in terms of best and worst practices, comprise new knowledge that is applicable to similar contexts. Frequently, lessons highlight strength and/or weakness in planning and implementation phases that affect performance, result, and impact. By using lessons drawn from review of the results of evaluation, individuals can figure out another strategies and/or actions needed for future planning and ultimately for improvement. The outcome of this step is also an action to provide the resourcing (Wickens \& Carswell, 2012) needed to go into the updated planning part of the cycle and continue the improvement (Taveira \& Smith, 2012).

The above-mentioned processes integrated to metacognition functions and components to make up a single consolidated system, 'Metacognition Management System (MMS)'. The MMS is made up a number of different clauses, each concentrating on the requirements involved in different aspects of such management system. The structure of MMS is illustrated in Figure 2. 


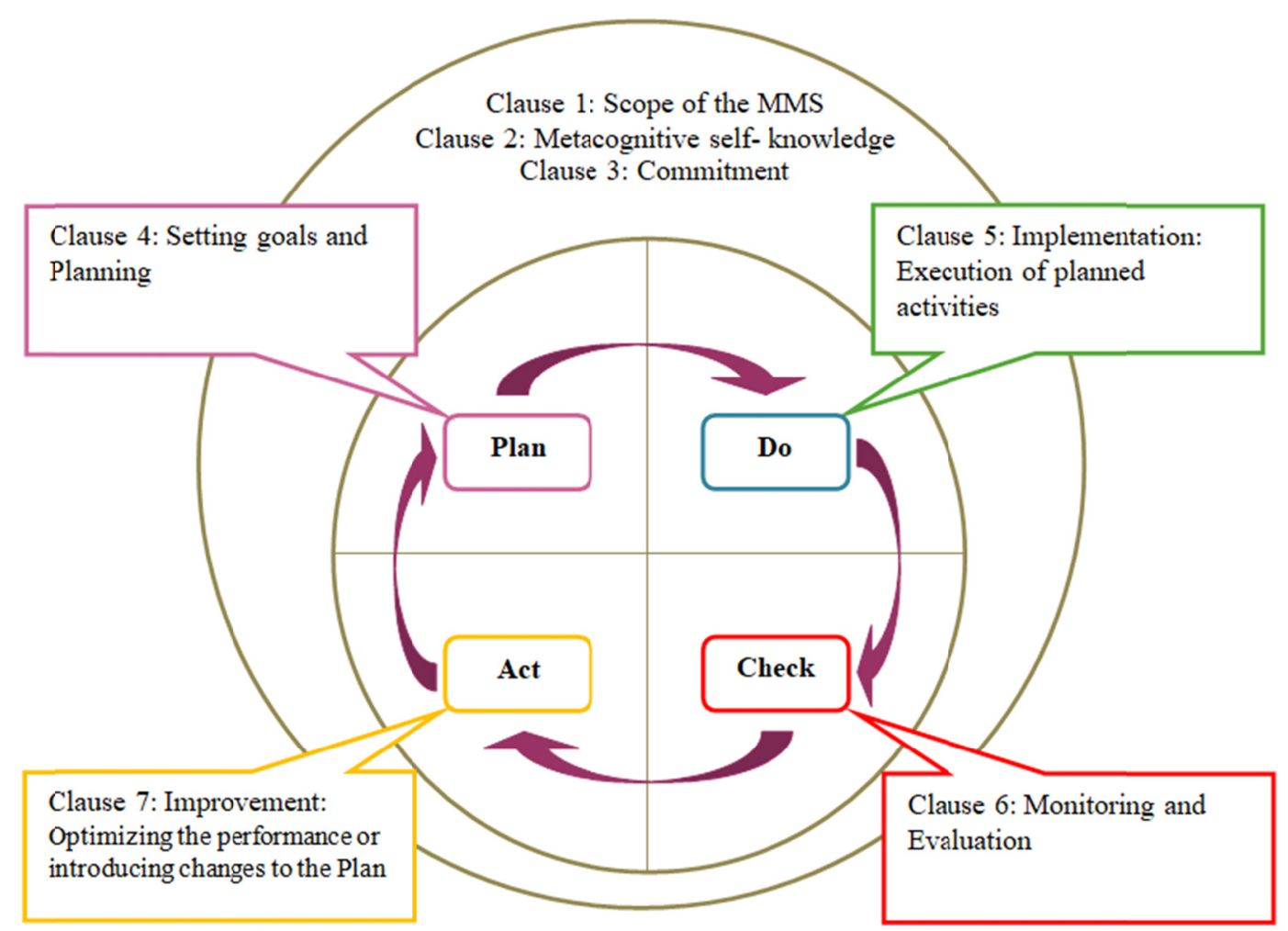

Figure 2. The structure of Metacognition Management System (Source: Adapted from Abuhav, 2017)

The clauses of the MMS are:

Clause 1: Scope of the MMS. The scope of the MMS defines in which areas and boundaries an individual is active and describes processes, operations, and products the MMS applies to. For example, the scope of MMS can be applied to a particular task (e.g. reading), a specific domain (e.g. learning and teaching) or in a whole life (e.g. personal growth, self-actualization, problem solving; decision making). A precise definition of scope is crucial since it determines which products are included under the MMS as well as the processes and activities that need to be planned and controlled.

Clause 2: Metacognitive self-knowledge. In general, when developing a management system, it is required to have knowledge of 'the context of the organization' in terms of the business environment in which organization conducts its business and realizes it products (Abuhav, 2017). This concept can be translated to the MMS under the umbrella of metacognitive knowledge. The metacognitive knowledge encompasses self-knowledge (accurate awareness about cognitive processes, self-efficacy, and motivational beliefs), the task context, situation or task related goals and strategies that influence the cognitive processes and products (Efklides, 2006; Vanderswalmen, et al., 2010). This clause refers to self-knowledge component of metacognitive knowledge. Self-knowledge comprises knowledge of inter/and intra-individual strengths and weaknesses (e.g. as a learner). This comprises the self-awareness of (a) one's own knowledge base, (b) ability to distinguish when one does not know much about something, (c) learning styles, (d) preferences, (e) making the appropriate match with task and strategy (Bostrum \& Lassen, 2006; Fink, 2003; Pintrich \& Schunk, 2002). Self-knowledge is a key element to develop a personal growth policy.

Clause 3: Commitment. Keeping in mind that the success of any management system (e.g. Quality Management System) depends on the commitment of the top management (Abuhav, 2017), we claim that the success of implementing MMS depends on the commitment of individuals to achieving their ultimate goal (e.g. personal growth) and related objectives. It means that individuals shall (i) take responsibility for establishing an effective MMS; (ii) establish improvement policy and related objectives; (iii) ensure availability of resources needed for the implementation of the MMS; (iv) ensure that the MMS and its related processes and activities achieve its intended results.

Clause 4: Goal setting and Planning. This clause directs individuals to look for either the possibility for improvement, 'opportunities', and come up with actions to develop these opportunities or address the probability 
of arriving at an unexpected state and come up with measures to mitigate them. We claim that MMS is a preventive tool that initiates activities for identifying (i) opportunities that help individuals in achieving their goals, or (ii) situations where intended outcomes would not be met. We maintain that metacognitive knowledge can be used to determine relevant opportunities or unexpected state. When planning the MMS, one determines which opportunities may be helpful in accomplishing objectives or which issues or problems may prevent or interrupt $\mathrm{him} /$ her from achieving his/her objective. These opportunities or issues derive from strengths or weaknesses aspects of self-knowledge accordingly. Undesired states may arise from task requirements and demands too. Therefore, one is to identify and then try to leverage them into improvement or propose ways to mitigate them.

Clause 5: Implementation. The following aspects are covered in this clause: organizing and implementing the plan. Organizing includes provision of resources, among others. Resources are one of the basic elements of MMS, therefore shall be defined and managed. Resources can be either internal such as cognitive capacities (Schunk, 2014) and motivational beliefs (Pintrich \& Schunk, 2002) or external such as Supportive social environment for metacognition (Lin, 2001). Resources are regarded as support tools for the MMS to meet an individual's goals. Therefore, based on the improvement policy and related objectives, individuals may determine (i) which resources are needed, (ii) which resources are available, (iii) how they can be deployed, and (iv) what are the limitations of resources. It should be noted that determining resources required for achieving the goals can be done in planning, and organizing and deployment of resources can be done in organizing phase. Further, strategies needed to achieve goals and objectives formulated and implementation arrangements (in terms of processes or activities) outlined in the planning phase will be employed for product (e.g.aa learning mathematics) realization.

Clause 6: Monitoring and evaluation. Monitoring (a continuous observation of performance of the process or its output) and evaluation (comparing a process or its output measurements with the specified criteria to determine the conformity of performance of the process or its output) (Abuhav, 2017) are vital for assessing the performance of the MMS. The data, that monitoring and evaluation provide, indicates the effectiveness of the MMS and its processes and the extent to which the MMS achieves its objectives. Hence, processes, resources, and process outputs are subject to monitoring and evaluation. The objective of monitoring and evaluation of: (i) processes are to review their effectiveness and efficiency; (ii) resources are to ensure that they are used effectively and efficiently in the realization processes; and (iii) process output is to ensure that they meet their specifications.

Clause 7: Improvement. Improvement can be defined as finding parameters that affect accomplishment of goals and implement appropriate changes. As a result, the MMS and its effectiveness will be enhanced. As stated before effectiveness of the MMS is a function of achievements of objectives of its processes. Collecting relevant data help individuals to make decision to introduce improvement to (i) planning and process input; (ii) use and deployment of resources; (iii) implementation (operation and activities); or (iv) process output. Applying the approach of the Plan-Do-Check-Act (PDCA) cycle promotes such improvement constantly.

\section{Experiment}

Based on the last question of the study, we determine the extent to which training of MMS influence metacognitive competencies among students. In what follows, information regarding experiment describes in brief.

\subsection{Population and Sample Size}

Thirty-two (out of 36 students) newly enrolled postgraduate students (Masters) who admitted for four departments of a public university in Tehran in 2018-2019 participated in the research on a voluntary basis. Since one of the participants in the experimental group left, we collected data from 31 students. Experimental and control groups consisted of 16 subjects ( 7 females, 9 male) and 15 subjects ( 7 females, 8 male) accordingly. The mean age for the sample, in both groups was between 26 and 30 years. Participants were invited to a dinner at the end of the experiment.

\subsection{Materials: Metacognition Management System Training Course (MMSTC)}

To design MMSTC, we used the ADDIE method that applies iterative process to design instructional interventions (Branch, 2009) based on the MMS Clauses and Plan-Do-Check-Act principles. Two experts through witnessing design process, making notes, suggesting changes, revising the course, approving and making judgment helped us to validate the MMSTC. The MMSTC modules and their learning outcomes illustrate in Figure 3. Each module deals with nature, component, function or processes of metacognition. 


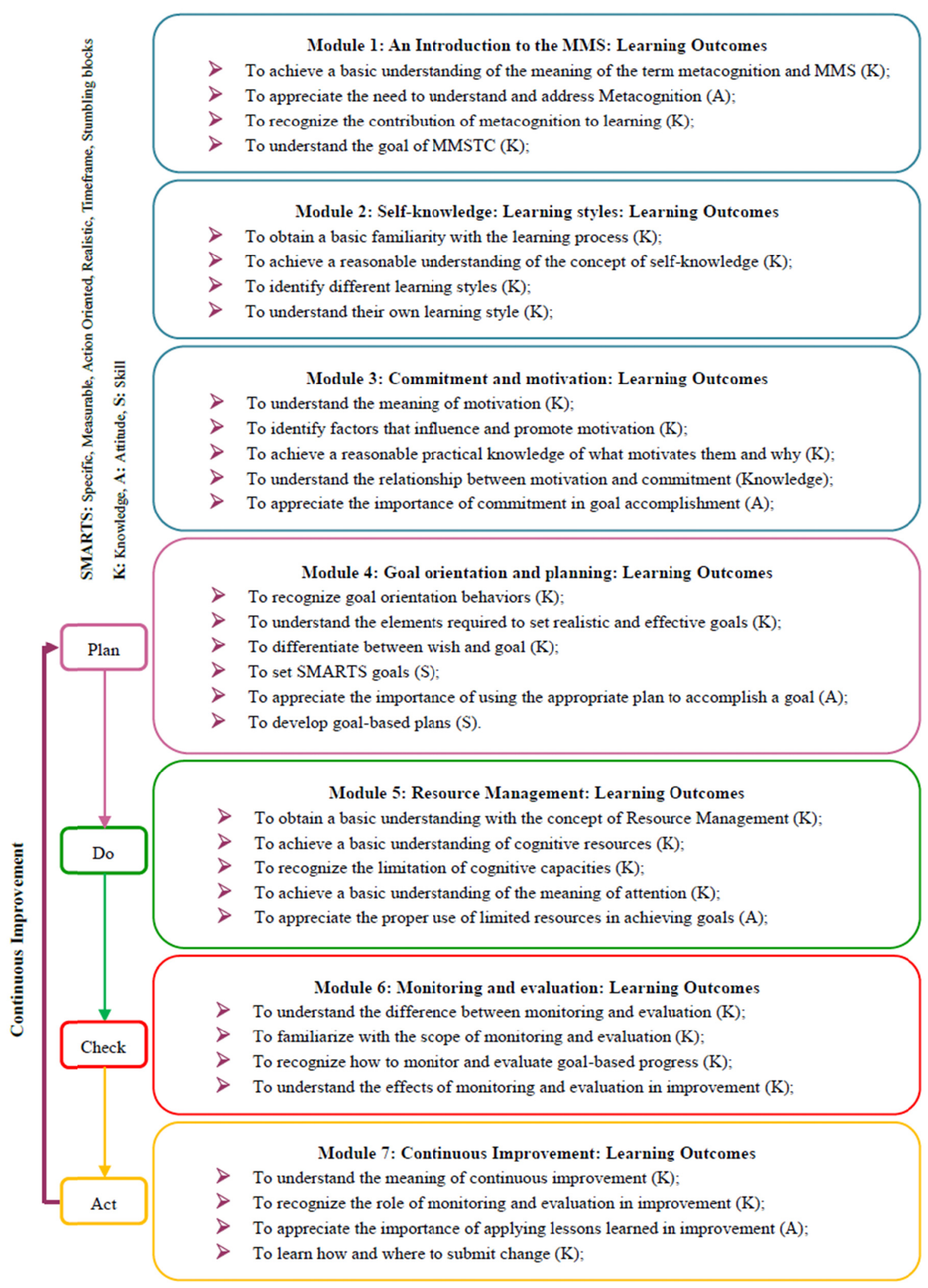

Figure 3. MMSTC framework, modules and learning outcomes 


\subsection{Instrument}

To measure different aspects of metacognitive competencies we used Metacognitive Awareness Inventory (MAI; Schraw \& Dennison, 1994).

\subsection{Research Hypotheses}

We formulate research hypotheses based on the different aspects of MAI which represented in Figure 4.

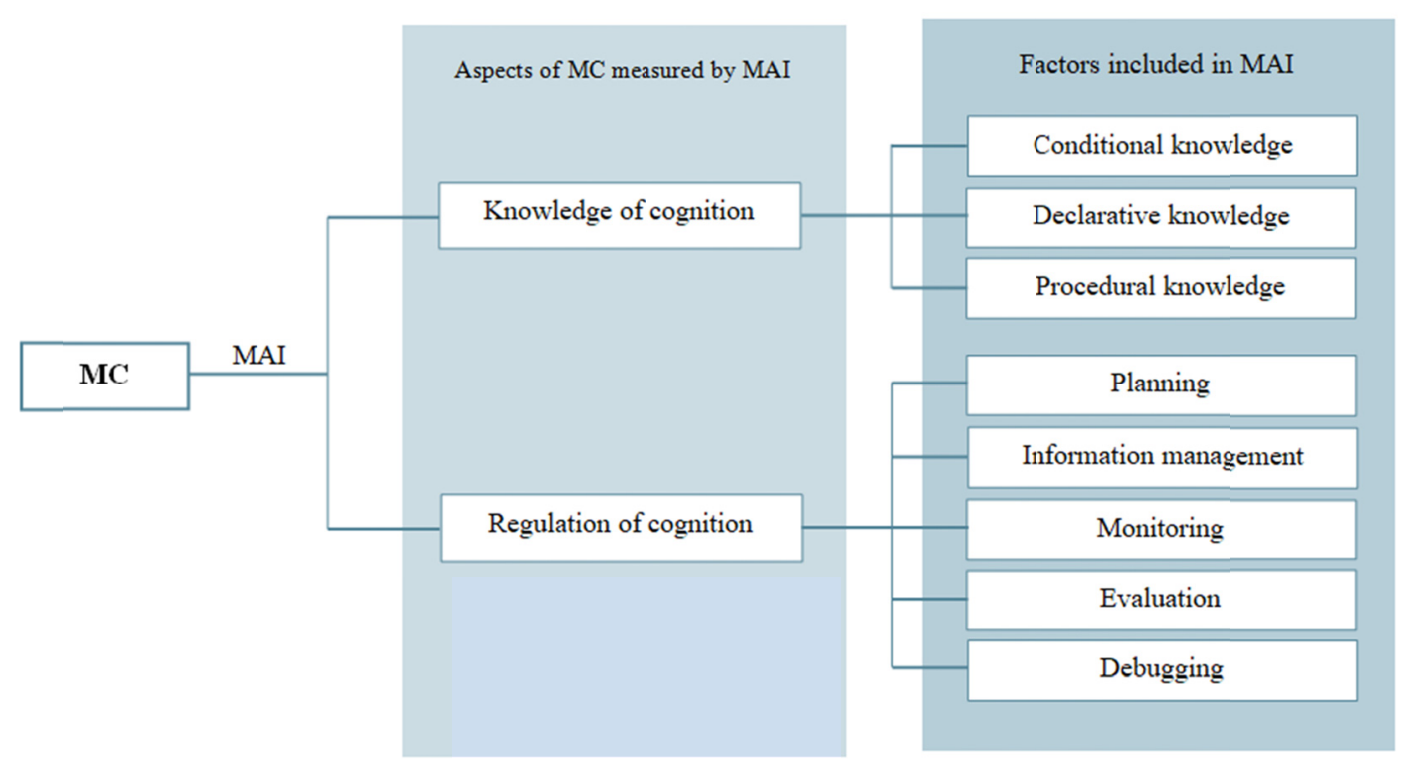

Figure 4. Graphical representation of research hypotheses

\subsection{Procedure}

After obtaining university approval and recruiting participants in groups, we conduct a pre-test to both experimental and control groups using MAI. Then, during two months (September and November of 2018), we gave MMSTC in eight ( $90 \mathrm{~min}$.) sessions to the experimental group only. Finally, we performed a post-test to both groups.

\subsection{Statistical Analysis}

To test the impact of MMSTC on metacognitive competencies, we conducted one-way Analysis of Covariance (ANCOVA). Prior of data analysis, we checked the assumptions of normality, dispersion, homogeneity of regression slopes, and homogeneity of variance for all hypotheses to ensure that all assumptions are met. Assumption of Linearity was analyzed creating a scatterplot for both experimental and control groups. Figure 5 demonstrates that a linear relationship exists between the dependent variable and covariate. 


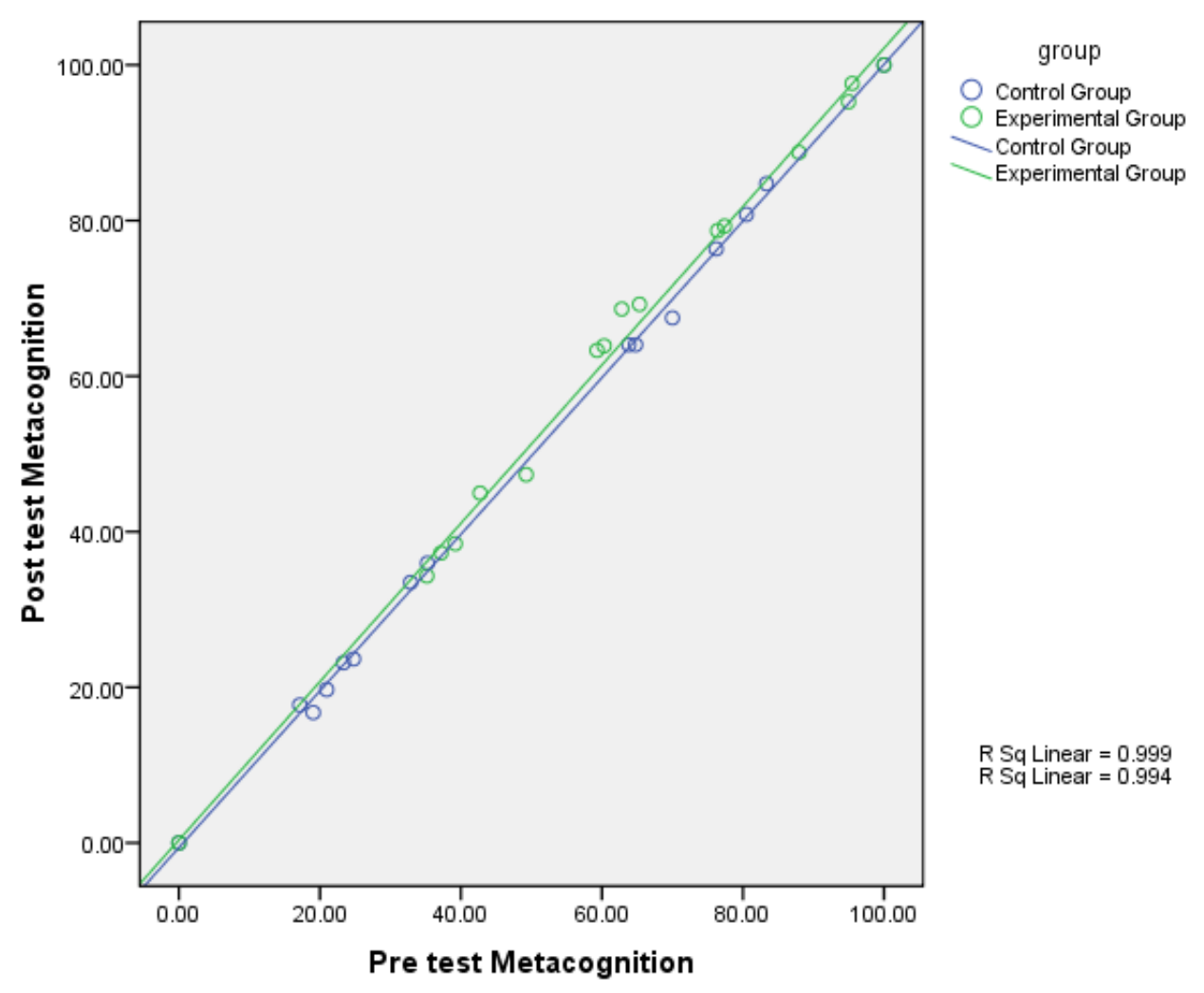

Figure 5. Scatterplot of pre-test, post-test among experimental and control groups

\section{Results}

After adjustment by covariates, as displayed in table 3 , a statistically significant main effect for metacognition was found with $F(1,28)=432.057, p=.000,(p<.05)$. The strength of the relationship between MMSTC and metacognitive competencies was substantial, with partial $\eta^{2}=.939,95 \%$ confidence intervals. The adjusted marginal means, as demonstrated in table 4, also showed the difference between experimental and control group after having control over the pre-test effects. A significant main effect was found for knowledge of cognition with $F(1,28)=57.467, p=.000,(p<.05)$ after covariates were adjusted (table 4$)$. The effect size was large with partial $\eta^{2}=.672,95 \%$ confidence intervals.

The ANCOVA results indicated mix results for components of knowledge of cognition including declarative knowledge $\left[F(1,28)=25.785, p=.000,(p<.05)\right.$, partial $\left.\eta^{2}=.479\right]$ and procedural knowledge $[F(1,28)=$ $13.318, p=.001,(p<.05)$, partial $\left.\eta^{2}=.322\right]$. However, no statistically significant main effect was found for conditional knowledge $[F(1,28)=3.306, P=.080,(p>.05)]$. Moreover, a significant main effect was found for regulation of cognition after adjustment by covariates (table 4), with $[F(1,28)=183.522, p=.000,(p<.05)$, partial $\eta^{2}=.8687,95 \%$ confidence intervals. The ANCOVA results also revealed statistically significant effect for components of regulation of cognition including planning $\left[F(1,28)=11.015, p=.003,(p<.05)\right.$, partial $\eta^{2}$ $=.282]$; information management $\left[F(1,28)=65.740, p=.000,(p<.05)\right.$, partial $\left.\eta^{2}=.701\right]$; monitoring $[F(1$, $28)=12.949, p=.001,(p<.05)$, partial $\left.\eta^{2}=.316\right]$; evaluation $[F(1,28)=30.307, p=.000,(p<.05)$, partial $\left.\eta^{2}=.520\right]$; and debugging $\left[F(1,28)=48.092, p=.000,(p<.05)\right.$, partial $\left.\eta^{2}=.632\right]$. 
Table 3. Results of analysis

\begin{tabular}{ccccccccc}
\hline & \multicolumn{3}{c}{ ANCOVA Results } & \multicolumn{3}{c}{ Adjusted Means } \\
\cline { 2 - 8 } & \multicolumn{4}{c}{ Experimental group } & \multicolumn{2}{c}{ Control group } \\
\cline { 2 - 8 } & $\mathrm{F}(1,28)$ & Sig. & Partial $\eta^{2}$ & $\mathrm{M}$ & $\mathrm{SE}$ & $\mathrm{M}$ & $\mathrm{SE}$ \\
\hline Metacognition & 432.057 & .000 & .939 & 60.047 & .447 & 54.470 & .460 \\
\hline Knowledge of Cognition & 57.467 & .000 & .672 & 109.02 & .876 & 99.622 & .904 \\
\hline Conditional Knowledge & 3.306 & .080 & .106 & 31.752 & .600 & 30.012 & .620 \\
\hline Declarative knowledge & 25.785 & .000 & .479 & 51.131 & .726 & 45.920 & .750 \\
\hline Procedural knowledge & 13.318 & .001 & .322 & 25.912 & .445 & 23.619 & .459 \\
\hline Regulation of Cognition & 183.522 & .000 & .868 & 227.649 & 1.001 & 203.940 & 1.032 \\
\hline Planning & 11.015 & .003 & .282 & 46.055 & .789 & 42.176 & .815 \\
\hline Information Management & 65.740 & .000 & .701 & 67.435 & .561 & 59.716 & .579 \\
\hline Monitoring & 12.949 & .001 & .316 & 43.877 & .714 & 40.271 & .729 \\
\hline Evaluation & 30.307 & .000 & .520 & 37.687 & .599 & 32.919 & .622 \\
\hline Debugging & 48.092 & .000 & .632 & 32.578 & .335 & 29.068 & .345 \\
\hline
\end{tabular}

\section{Discussion}

This finding is in line with Amzil (2014) study which concludes that a 5-session metacognitive intervention lead to improvement in metacognitive abilities of college students. It is also along the lines of Schraw (2002) study that knowledge of cognition and regulation of cognition were improved using instructional strategies. It is also corresponding to Serra and Metcalfe (2009) study, which shows that even brief and compact metacognitive strategy training interventions improve the monitoring and control processes.

The findings also consistent with Pelton's (2019) report reflecting that direct instruction on metacognition including its definition, goal setting, planning, monitoring and evaluation have a positive impact on using metacognitive strategies. Therefore, this finding is another evidence that metacognition is teachable and those who exposed to metacognitive interventions improved their metacognitive competencies.

Using multidimensional metacognitive intervention in this study and obtaining meaningful results is in line with the reports of Kramaski, Mevarech, and Lieberman (2001) which reflected that multidimensional metacognitive interventions lead to better ability in solving problem and metacognitive awareness than one-dimensional metacognition training. However, the results are in consistent with Dignath and Büttner (2010) study. They investigated the impacts of self-regulation training on learning and strategy-use among primary and secondary students. They found that the best result can be obtained when a combination of two strategies such as planning-monitoring or planning-evaluation were applied. Teaching one of them (e.g. planning) in isolation or a combination of all of them lead to less effective result.

Results showing that students who were exposed to MMSTC obtained better scores in regulation of cognition are incongruent with Doyle's (2013) studies. Using MAI in a quasi-experimental research design, he investigated the impacts of a metacognitive intervention on pre-nursing students' metacognition and found that students scored higher in knowledge of cognition compared to regulation of cognition. Results showing better score in declarative knowledge among students who received MMSTC are also inconsistent with the results of the study of Sugiharto, Corebima, and Susilo (2018). Using MAI they compared conditional, procedural, and declarative knowledge among biology students and found that conditional knowledge was most highly developed in their samples, followed by procedural and declarative knowledge, accordingly. They also found that the performance of procedural and declarative knowledge is at the same level under certain circumstances.

\section{Conclusion}

The conceptual framework presented in this study offers a new approach to the study of metacognition by integrating functions, processes and components of metacognition involved in classic, descriptive and procedural models using a business oriented methodology. To develop such conceptual framework, the idea of management system which is a set of interrelated elements such as functions, resources and processes and integrates into a logical and coherent system was employed. For the purpose of this study, the concepts that are considered as metacognitive skill or strategy, are considered as processes and include planning, implementation, monitoring, and evaluation. These processes integrated to other elements of metacognition to make up a single consolidated system, namely, 'Metacognition Management System (MMS)'.

To establish interrelationship among the elements of such system, continuous improvement cycle 
(Plan-Do-Check-Act) is employed. Hence, the MMS not only covers all components (e.g. knowledge and regulation), processes (e.g. planning and monitoring), and functions (e.g. motivation) of metacognition but also integrates the PDCA principles to demonstrate the developmental nature of metacognition. The MMS is made up a number of different clauses, each concentrating on the requirements involved in different aspects of metacognition. The clauses of the MMS include the scope of the MMS, metacognitive self-knowledge, commitment, goal setting and planning, implementation, monitoring and evaluation and improvement. These clauses are equivalent to elements of well-known management systems. At the last step, the results of our experiment regarding the role of teaching MMS demonstrated that students who received MMSTC have enhanced their metacognitive competencies.

\section{Implications}

\subsection{Implications for Theory}

By incorporating management discipline into theoretical models of metacognition we tried to provide useful insight into the study of metacognition and deal with the fuzziness of the relationship between metacognition elements. To advance toward the conceptual framework of metacognition (MMS), we advise researchers to further examine this model and refine it by revealing more details about variables might include in each clauses of MMS. To provide practical and empirical supports for this study, we call for further theoretical researches on the configuration and application of MMS and identification of other elements that should be added to MMS.

\subsection{Implications for Designing Metacognitive Intervention}

Developing an intervention targeting improvement in general metacognitive abilities is a challenging task (Vos \& De Graaff, 2004). Over the past four decades, there have been independent and substantive efforts to design metacognitive interventions to study metacognition from a variety of perspectives. Most of these interventions were designed using two basic approaches: strategy training and creating a supportive social environment for metacognition. Contents adopting these approaches were either knowledge about the specific domain or knowledge about the self-as-learner (self-knowledge) (Lin, 2001). Lin (2001) suggests that in designing metacognitive interventions a systematic approach shall be employed to realize combination of these approaches and contents and finding ways to build self-knowledge (e. g. as learner).

Consistent with Lin's suggestion, a systematic approach adopted to develop the MMS and MMSTC, accordingly. The results of this study suggest that students who received MMSTC have enhanced their metacognitive competencies. However, can this intervention be broadly implemented in educational setting and can be achieved in its chief goal which is improving students' metacognitive competencies? Future attempts are needed to integrate phenomena involved in metacognition theories to develop a multidimensional metacognitive intervention and using experimental studies to examine its effectiveness.

\section{References}

Abuhav, I. (2017). ISO 9001: 2015-A complete guide to quality management systems. CRC Press. https://doi.org/10.1201/9781315369808

Amzil, A. (2014). The effect of a metacognitive intervention on college students' reading performance and metacognitive skills. Journal of Educational and Developmental Psychology, 4(1), 27. https://doi.org/10.5539/jedp.v4n1p27

Azevedo, R., \& Aleven, V. (2013). Metacognition and learning technologies: An overview of current interdisciplinary research. In International handbook of metacognition and learning technologies (pp. 1-16). Springer, New York, NY. https://doi.org/10.1007/978-1-4419-5546-3_1

Azevedo, R., \& Cromley, J. G. (2004). Does training on self-regulated learning facilitate students' learning with hypermedia? Journal of educational psychology, 96(3), 523. https://doi.org/10.1037/0022-0663.96.3.523

Blummer, B., \& Kenton, J. M. (2014). Improving student information search: A metacognitive approach. Chandos Publishing. https://doi.org/10.1533/9781780634623.23

Boehm-Davis, D. A., \& Holt, R. W. (2004). The science of human performance: methods and metrics. Advances in Human Performance and Cognitive Engineering Research, 5, 157-193. https://doi.org/10.1016/S1479-3601(04)05003-9

Boiral, O., \& Heras-Saizarbitoria, I. (2015). Management System Standards. In S. M. Dahlgaard-Park (Ed.), The SAGE Encyclopedia of Quality and the Service Economy (pp. 390-395). SAGE Publications.

Bostrum, L., \& Lassen, L. M. (2006). Unravelling Learning, Learning Styles, Learning Strategies and 
Metacognition. Education and Training, 48(2/3), 178-189. https://doi.org/10.1108/00400910610651809

Branch, R. M. (2009). Instructional Design: The ADDIE Approach. Springer. https://doi.org/10.1007/978-0-387-09506-6

Bryce, D. (2007). Investigating the relationship between metacognitive skill and executive functions: A pilot study to assess developmental changes in four to eight-year-olds (Unpublished MPhil thesis). University of Cambridge, UK.

Bryce, D., \& Whitebread, D. (2008). Investigating the relationship between metacognitive skills and executive functions. Paper presented at 3rd Biennial Meeting of EARLI Special Interest Group 16: Metacognition, Ioannina, Greece.

Csíkos, C., \& Steklács, J. (2010). Metacognition-based reading intervention programs among fourth-grade Hungarian students. In Trends and prospects in metacognition research (pp. 345-366). Springer, Boston, MA. https://doi.org/10.1007/978-1-4419-6546-2_16

Desoete, A. \& Roeyers, H. (2005). Cognition and metacognition in children with mathematics learning disabilities. In P. Ghesquière, \& A. J. J. M. Ruijssenaars (Eds.), Learning Disabilities: A challenge to teaching and instruction (pp. 65-89). Leuven University Press.

Desoete, A. (2007a). Evaluating and improving the mathematics teaching-learning process through metacognition? Electronic Journal of Research in Educational Psychology, 5(3), 705-730.

Desoete, A. (2007b). Students with mathematical disabilities in Belgium: from definition, classification and assessment to STICORDI devices. In T. E. Scruggs, \& M. A. Mastropieri (Eds.), Advances in Learning and Behavioral Disabilities, Vol. 20. International Perspectives (pp. 181-222). Amsterdam \& Oxford: Elsevier Press. https://doi.org/10.1016/S0735-004X(07)20008-4

Desoete, A. (2011). The Enigma of Mathematical Learning Disabilities: Metacognition or STICORDI, That's the Question, In D. J. Hacker, J. Dunlosky, \& A. C. Graesser (Eds.), Handbook of metacognition in education (pp. 206-218). New York: Routledge.

Dignath, C., \& Büttner, G. (2008). Components of fostering self-regulated learning among students. A meta-analysis on intervention studies at primary and secondary school level. Metacognition and Learning, 3, 231-264. https://doi.org/10.1007/s11409-008-9029-x

Doyle, B. P. (2013). Metacognitive awareness: Impact of a metacognitive intervention in a pre-nursing course (LSU Doctoral Dissertations). Retrieved from https://digitalcommons.lsu.edu/gradschool_dissertations/2644

Efklides, A. (2006). Metacognition and affect: What can metacognitive experiences tell us about the learning process? Educational research review, 1(1), 3-14. https://doi.org/10.1016/j.edurev.2005.11.001

Eker, C. (2014). The Effect of Teaching Practice Conducted by Using Metacognition Strategies on Students' Reading Comprehension Skills. International Online Journal of Educational Sciences, 6(2), 269-280. https://doi.org/10.15345/iojes.2014.02.002

Fink, L. D. (2003). Creating Significant Learning Experiences. San Francisco, CA: Jossey-Bass.

Flavell, J. H. (1979). Metacognition and cognitive monitoring: a new area of cognitive-developmental inquiry. American Psychologist, 34, 906-911. https://doi.org/10.1037/0003-066X.34.10.906

Gama, C. A. (2005). Integrating metacognition instruction in interactive learning environments (Doctoral dissertation, University of Sussex). https://doi.org/10.1007/978-3-540-30139-4_63

Gollwitzer, P. M., \& Sheeran, P. (2006). Implementation intentions and goal achievement: A meta-analysis of effects and processes. In M. P. Zanna (Ed.), Advances in experimental social psychology (Vol. 38, pp. 69-119). San Diego, CA: Elsevier. https://doi.org/10.1016/S0065-2601(06)38002-1

Gourgey, A. (1998). Metacognition in Basic Skills Instruction. Instructional Science, 26(1), 81-96. https://doi.org/10.1023/A:1003092414893

Gourgey, A. (2001). Metacognition in basic skills instruction. In H. J. Hartman (Ed.), Metacognition in learning and instruction: Theory, research and practice (pp. 17-32). Boston, MA: Kluwer. https://doi.org/10.1007/978-94-017-2243-8_2

Hacker, D. J., Keener, M. C., \& Kircher, J. C. (2009). Writing is Applied Metacognition. In D. J. Hacker, J. Dunlosky, \& A. C. Graesser (Eds.), Handbook of Metacognition in Education (pp. 154-172). Routledge. 
Hasan, Z., \& Hossain, M. S. (2018). Improvement of Effectiveness by Applying PDCA Cycle or Kaizen: An Experimental Study on Engineering Students. Journal of Scientific Research, 10(2), 159-173. https://doi.org/10.3329/jsr.v10i2.35638

Holland, R. W., Aarts, H., \& Langendam, D. (2006). Breaking and creating habits on the working floor: A field-experiment on the power of implementation intentions. Journal of Experimental Social Psychology, 42(6), 776-783. https://doi.org/10.1016/j.jesp.2005.11.006

Hollingworth, R., \& McLoughlin, C. (2001). Developing science students' metacognitive problem solving skills online. Australian Journal of Educational Technology, 17(1), 50-63. https://doi.org/10.14742/ajet.1772

Hoyle, R. H., \& Davisson, E. K. (2016). Varieties of self-control and their personality correlates. Handbook of self-regulation: Research, theory, and applications, 396-413.

Kartikowati, R. S. (2013). The technique of" plan do check and act" to improve trainee teachers' skills. Asian Social Science, 9(12), 268. https://doi.org/10.5539/ass.v9n12p268

Kettner, P. M., Moroney, R. M., \& Martin, L. L. (2015). Designing and managing programs: An effectiveness-based approach. Sage Publications.

Koole, S. L., \& Aldao, A. (2016). The self-regulation of emotion: theoretical and empirical advances. Handbook of self-regulation.

Kramarski, B., Mevarech, Z. R., \& Lieberman, A. (2001). Effects of multilevel versus unilevel metacognitive training on mathematical reasoning. The Journal of Educational Research, 94(5), 292-300. https://doi.org/10.1080/00220670109598765

Krizan, Z., \& Hisler, G. (2016). The essential role of sleep in self-regulation. Handbook of self-regulation, 182-197.

Kuhn, D. (2000). Metacognitive development. Current Directions in Psychological Science, 9, 178-181. https://doi.org/10.1111/1467-8721.00088

Kymal, C., Gruska, G., \& Reid, R. D. (2015). Integrated Management Systems: QMS, EMS, OHSMS, FSMS including Aerospace, Service, Semiconductor/Electronics, Automotive, and Food. Quality Press.

Lazonder, A. W., \& Rouet, J. (2008). Information problem solving instruction: Some cognitive and metacognitive issues. Computers in Human Behavior, 24(3), 753-65. https://doi.org/10.1016/j.chb.2007.01.025

Liedtke, C. A. (2012). The Application of Policy Deployment in Indian Companies. Presented at the Asian Network for Quality Congress, Hong Kong, August 1, 2012.

Lin, X. D. (2001). Designing metacognitive activities. Educational Technology Research \& Development, 49(2), 23-40. https://doi.org/10.1007/BF02504926

Locke, E. A., \& Latham, G. P. (Eds.). (2013). New developments in goal setting and task performance. Routledge. https://doi.org/10.4324/9780203082744

McDavid, J., \& Hawthorn, L. (2006). Program evaluation and performance measurement: An introduction to practice. Thousand Oaks, CA: Sage.

Morgeson, F. P., Campion, M. A., \& Bruning, P. F. (2012). Job and team design. Handbook of human factors and ergonomics, 441-474. https://doi.org/10.1002/9781118131350.ch15

Panahandeh, E., \& Asl, S. E. (2014). The effect of planning and monitoring as metacognitive strategies on Iranian EFL learners' argumentative writing accuracy. Procedia-Social and Behavioral Sciences, 98, 1409-1416. https://doi.org/10.1016/j.sbspro.2014.03.559

Papaleontiou-Louca, E. (2008). Metacognition and theory of mind. England: Cambridge Scholars Press.

Papaleontiou-Louca, E. (2014). Metacognition. In D. Phillips (Ed.), Encyclopedia of Educational Theory and philosophy (pp. 523-526). Thousand Oaks, CA: SAGE Publications.

Papies, E. K., \& Aarts, H. (2016). Automatic self-regulation: From habit to goal pursuit. Handbook of self regulation: Research, theory, and applications.

Papies, E. K., Aarts, H., \& DeVries, N. K. (2009). Planning is for doing: Implementation intentions go beyond the mere creation of goal-directed associations. Journal of Experimental Social Psychology, 45, 1148-1151. https://doi.org/10.1016/j.jesp.2009.06.011 
Pelton, J. A. (2019). Teaching about Learning: The Effects of Instruction on Metacognition in a Sociological Theory Course. Teaching Sociology, 47(4), 325-338. https://doi.org/10.1177/0092055X19861684

Peña-Ayala, A., \& Cárdenas, L. (2015). A conceptual model of the metacognitive activity. In Metacognition: Fundaments, applications, and trends (pp. 39-72). Springer, Cham. https://doi.org/10.1007/978-3-319-11062-2_3

Pintrich, P. R., \& Schunk, D. H. (2002). Motivation in Education: Theory, Research and Applications. Upper Saddle, NJ: Prentice Hall Merrill.

Pintrich, P. R., Wolters, C. A., \& Baxter, G. P. (2000). Assessing metacognition and self-regulated learning.

Rozencwajg, R. P. (2003). Metacognitive factors in scientific problem solving strategies. European Journal of Psychology of Education, 18(3), 281-294. https://doi.org/10.1007/BF03173249

Schraw, G. (2001). Promoting general metacognitive awareness. In Metacognition in learning and instruction (pp. 3-16). Springer, Dordrecht. https://doi.org/10.1007/978-94-017-2243-8_1

Schraw, G., \& Dennison, R. S. (1994). Assessing metacognitive awareness. Contemporary Educational Psychology, 19, 460-475. https://doi.org/10.1006/ceps.1994.1033

Schraw, G., \& Gutierrez, A. P. (2015). Metacognitive strategy instruction that highlights the role of monitoring and control processes. In Metacognition: Fundaments, applications, and trends (pp. 3-16). Springer. https://doi.org/10.1007/978-3-319-11062-2_1

Schunk, D. H. (2014). Learning Theories. In D. Phillips (Ed.), Encyclopedia of Educational Theory and philosophy (pp. 466-470). Thousand Oaks, CA: SAGE Publications.

Serra, M. J., \& Metcalfe, J. (2009). Effective Implementation of Metacognition. Handbook of metacognition in education, 278.

Sperling, R. A., Howard, B. C., Staley, R., \& Du Bois, N. (2004). Metacognition and regulation of cognition. Contemporary Educational Psychology, 27, 51-79. https://doi.org/10.1006/ceps.2001.1091

Sugiharto, B., Corebima, A. D., \& Susilo, H. (2018). A comparison of types of knowledge of cognition of preservice biology teachers. In Asia-Pacific Forum on Science Learning \& Teaching (Vol. 19, No. 1).

Taveira, A. D., \& Smith, M. J. (2012). Social and Organizational Foundations of Ergonomics. In G. Salvendy (Ed.), Handbook of Human Factors and Ergonomics (4th ed., pp. 274-297). John Wiley \& Sons. https://doi.org/10.1002/9781118131350.ch9

Vanderswalmen, R., Vrijders, J., \& Desoete, A. (2010). Metacognition and Spelling Performance in College Students, In A. Efklides, \& P. Misailidi (Eds.), Trends and Prospects in Metacognition Research (pp. 367-394). Springer. https://doi.org/10.1007/978-1-4419-6546-2_17

Veenman, M. V. (2012). Metacognition in Science Education: Definitions, Constituents, and Their Intricate Relation with Cognition. In Metacognition in science education (pp. 21-36). Springer, Dordrecht. https://doi.org/10.1007/978-94-007-2132-6_2

Veenman, M. V. J., Van Hout-Wolters, B. H. A. M., \& Afflerbach, P. (2006). Metacognition and learning. Conceptual and methodological considerations. Metacognition Learning, 1, 3-14. https://doi.org/10.1007/s11409-006-6893-0

Veenman, M. V., \& Alexander, P. (2011). Learning to self-monitor and self-regulate. Handbook of research on learning and instruction, 197-218.

Vos, H., \& De Graaff, E. (2004). Developing metacognition: A basis for active learning. European Journal of Engineering Education, 29(4), 543-548. https://doi.org/10.1080/03043790410001716257

White, B. Y., \& Frederiksen, J. R. (2005). A theoretical framework and approach for fostering metacognitive development. Educational Psychologist, 40(4), 211-223. https://doi.org/10.1207/s15326985ep4004_3

Whitebread, D., \& Cárdenas, V. G. (2012). Self-regulated learning and conceptual development in young children: The development of biological understanding. In Metacognition in Science Education (pp. 101-132). Springer, Dordrecht. https://doi.org/10.1007/978-94-007-2132-6_6

Wickens C. D., \& Carswell C. M. (2012). Information Processing. In G. Salvendy (Ed.), Handbook of Human Factors and Ergonomics (4th ed., pp. 117-161) John Wiley \& Sons. https://doi.org/10.1002/9781118131350.ch5 
Wilson, D., \& Conyers, M. (2016). Teaching Students to Drive Their Brains. ASCD.

Zhao, P. (2014). The Model of "Plan Do Check and Act" to Improve Chinese EFL Learners' Writing Strategies. Higher Education of Social Science, 7(1), 107-112.

Zimmerman, B. J. (2000). Attaining Self-Regulation: A social cognitive perspective. In M. Boekaerts, P. R. Pintrich, \& M. Zeidner (Eds.), Handbook of self-regulation: Theory, research, and applications (pp. 13-41). San Diego, CA: Academic Press.

Zohar, A., \& Dori, Y. J. (Eds.). (2011). Metacognition in science education: Trends in current research (Vol. 40). Springer Science \& Business Media. https://doi.org/10.1007/978-94-007-2132-6_1

\section{Copyrights}

Copyright for this article is retained by the author(s), with first publication rights granted to the journal.

This is an open-access article distributed under the terms and conditions of the Creative Commons Attribution license (http://creativecommons.org/licenses/by/4.0/). 